Syed Majid Hussain, MBBS, MS (ENT-HNS)' Rauf Ahmad, MBBS, MS (ENT-HNS) ${ }^{1}$

'Department of Ear Nose Throat Head and Neck Surgery Sri Maharaja Hari Singh Hospital Karan Nagar Srinagar, Jammu \& Kashmir, India

Correspondence: Syed Majid Hussain, MBBS, MS (ENT-HNS) Registrar, Department of ENT - HNS

Sri Maharaja Hari Singh Hospital

Karan Nagar Srinagar, Jammu \& Kashmir 190001

India

Phone: 09596478093

E-mail: majidhussain73@gmail.com

Reprints will not be available from the authors.

The authors declared that this represents original material that is not being considered for publication or has not been published or accepted for publication elsewhere, in full or in part, in print or electronic media; that the manuscript has been read and approved by all the authors, that the requirements for authorship have been met by each author, and that each author believes that the manuscript represents honest work.

Disclosures: The authors signed disclosures that there are no financial or other (including personal) relationships, intellectual passion, political or religious beliefs, and institutional affiliations that might lead to a conflict of interest.

\title{
Typical Laryngeal Carcinoid Recurrence and its Management by Conservative Surgery
}

\section{Methods:}

\author{
Design: Case Report \\ Setting: Tertiary Government Hospital \\ Patient: One
}

ABSTRACT

Objectives: Recurrence of a typical laryngeal carcinoid is extremely rare after surgery with tumor-free margins on histopathology. We present a rare case of typical laryngeal carcinoid that recurred after eight years and was managed by conservative surgery.

Results: A known case of typical laryngeal carcinoid treated eight years back reported again with the same symptoms he previously had. On evaluation local tumor recurrence was identified with a negative metastatic workup. The patient was subjected to microlaryngeal excision which was adequate histopathologically. He has had no evidence of disease on follow up of two years.

Conclusion: A typical laryngeal carcinoid tumor may present differently and recur locally but conservative surgery is still an option if local nodal and distant metastatic spread is ruled out.

Key words: neuroendocrine tumor,typical laryngeal carcinoid, microlaryngeal excision. hemoptysis

Laryngeal neuroendocrine tumors represent a heterogeneous group of neoplasms that have been classified into carcinoids (typical and atypical), small cell carcinomas \& paragangliomas.' These are the most common non-squamous tumors of the larynx and account for about 0.5 - $1 \%$ of all laryngeal tumors. ${ }^{2,3}$ The clinical features and gross endoscopic picture are very similar to a typical laryngeal carcinoma for which it can be mistaken. However histopathological and immunohistochemical studies are prerequisites for recognition of the tumor and its subclass that has a direct bearing on the treatment and prognosis. A typical carcinoid is rarest, accounting for about $3 \%$ of all neuroendocrine tumors, and has the most favorable prognosis because local invasion, nodal and distant metastases are very rare. Local excision with tumor-free margins is recommended with regular follow up to detect any recurrence.

\section{CASE REPORT}

A 55-year-old male was referred by a primary care physician to our department with three months history of recurrent episodes of hemoptysis and foreign body sensation in the throat. $\mathrm{He}$ 


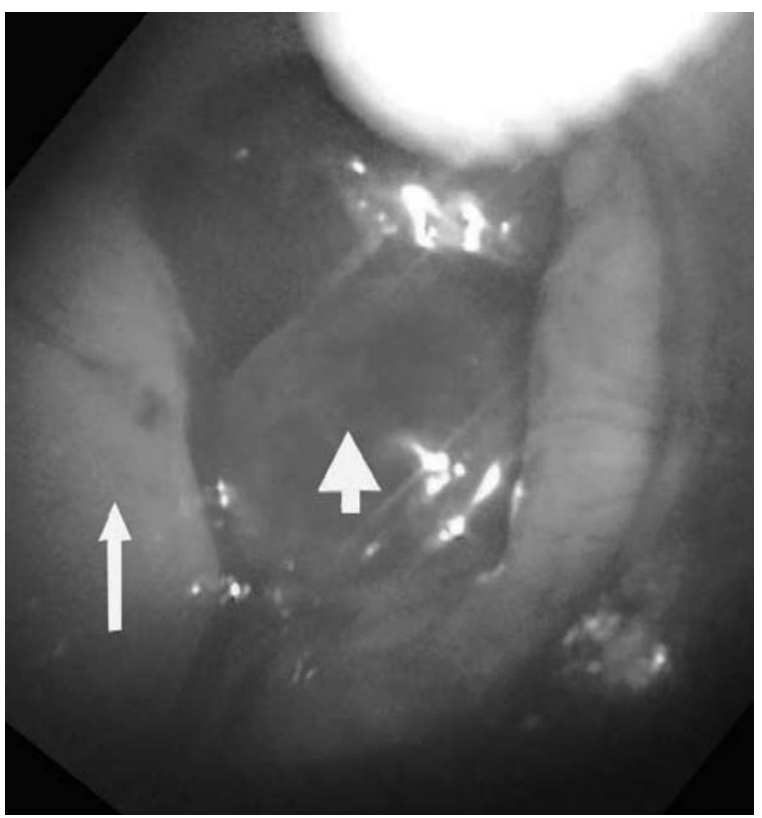

Figure 1. Smooth surfaced tumor (arrowhead) on right arytenoid. Endotracheal tube (arrow) endolaryngeal appearance.

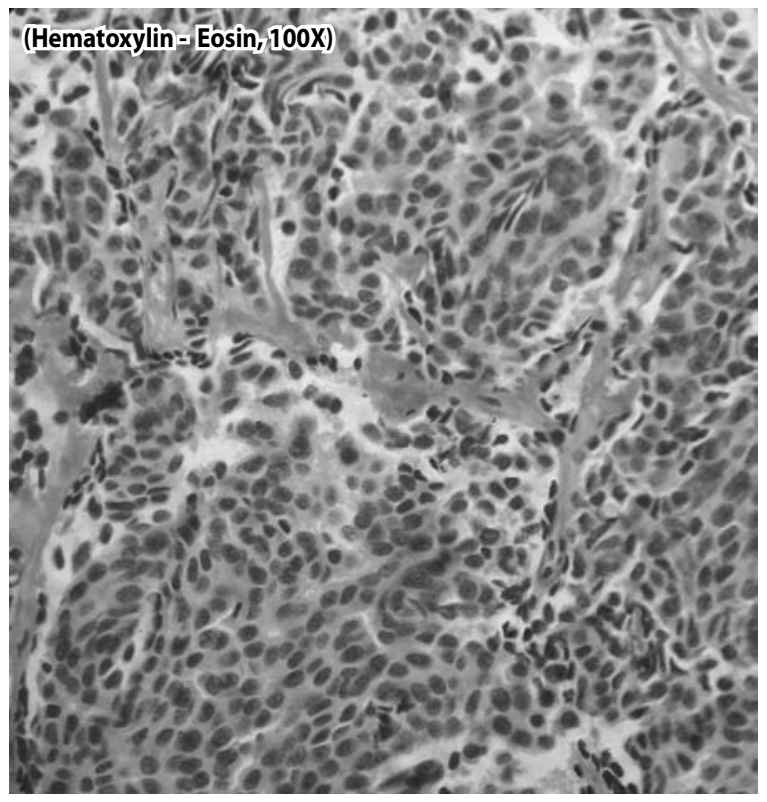

Figure 2. High power magnification showing sheets of cells with well defined round/oval nuclei and pericellular hyalinized stroma.

had no significant past medical or surgical history. He denied any voice or swallowing problems and there were no complaints referable to nose, nasopharynx and ear. The general physical and systemic examination was unremarkable. Indirect laryngoscopy revealed a reddish smooth surfaced mass over the right arytenoid and adjacent aryepiglottic fold with normal vocal cord and mobility. The rest of the ENT examination was unremarkable.

A contrast-enhanced CT scan of the neck showed an enhancing mass over the right arytenoid and adjoining posterior aryepiglottic fold which was well localized. There was no vocal cord or paraglottic space involvement and no significant cervical lymphadenopathy was detected. A direct laryngoscopic excision of the mass was carried out uneventfully. Histopathology revealed a welldifferentiated neuroendocrine tumor with negative margins while immunohistochemical staining was positive for cytokeratin, serotonin, chromogranin and synaptophysin thereby confirming the carcinoid morphology. A complete metastatic workup had negative results.

The patient did not follow up as advised. Eight years later he again complained of similar symptoms which were increasing in severity. On examination tumor recurrence was noted in the same area. The patient was again subjected to direct laryngoscopic excision which was reported as well-differentiated carcinoid with tumor-free margins. A fresh metastatic workup was again negative. The patient has been following up regularly for the last two years and has had no evidence of disease until submission of this report.

\section{DISCUSSION}

Since the first description of carcinoid by Oberndorfer in $1907^{4}$ as a distinct form of carcinoma, more than 500 cases of neuroendocrine tumors of the larynx have been reported. These tumors originate from the Amine Precursor Uptake and Decarboxylase (APUD) cells or the diffuse neuroendocrine cell system. ${ }^{5}$ Typical laryngeal carcinoid represents a rarest entity with no more than 14 cases reported so far with an overwhelming male preponderance and an average age of affliction of 58 years. ${ }^{6,7}$

In contrast to usual clinical features of dysphonia, dysphagia and otalgia the patient presented with foreign body sensation in the throat and recurrent hemoptysis, the latter being an unknown presentation of this disease. Laryngoscopic examination usually reveals a sessile or polypoidal smooth surfaced pinkish-red mass with well-defined borders most frequently seen in the supraglottis, either on the aryepiglottic folds or arytenoids.7 A contrast-enhanced CT is essential for evaluating local tumor invasion and lymph nodal status.

Uniform cells with granular cytoplasm and centrally-placed oval or round nuclei and a pericellular hyalinized stroma characterize this tumor microscopically. Mitosis, nuclear atypia and necrosis are conspicuously lacking. Positive staining for cytokeratin, chromogranin and synaptophysin indicates an APUD cell lineage. ${ }^{8}$

While surgery is the treatment of choice, the amount of excision varies with the size of tumor ranging from local excision to partial 
laryngectomy. Neck dissection is indicated in patients with positive nodal disease clinically or radiologically, and the role of elective neck dissection is limited with only 4 of 13 patients showing node metastasis and only one death due to tumor itself.' Radiotherapy and chemotherapy are reserved for advanced tumors. ${ }^{9}$

Although tumor recurrence has been reported after many symptomfree years as in our case, ${ }^{10}$ it is still possible to manage recurrence by local excision with minimal disturbance of laryngeal functions, subject to the absence of local and distant tumor spread, but regular followup is advised. The overall prognosis in such cases is excellent. ${ }^{11}$ Hence, a typical laryngeal carcinoid tumor may present differently and recur locally but conservative surgery is still an option if local nodal and distant metastatic spread is ruled out.

\section{ACKNOWLEDGMENT}

We would like to thank Dr. A R Khan, Consultant Pathologist for his contribution to the histopathological aspect of the tumor.

\section{REFERENCES}

1. Shanmugaratnam K, Sobin LH. The World Health Organization histological classification of tumors of the upper respiratory tract and ear: A commentary on the second edition. Cancer. 1993 Apr 15;71(8): 2689 - 97

2. Ferlito $A$, Silver $C E$, Bradford $C R$, Rinaldo $A$. Neuroendocrine neoplasms of the larynx: an overview. Head Neck. 2009 Dec; 31 (12): 1634 - 46.

3. Capelli M, Bertino G, Morbini P, Villa C, Zorzi S, Benazzo M. Neuroendocrine carcinomas of the upper airways: A small case series with histopathological considerations. Tumori. 2007 Sep-Oct; 93(5):499-503.

4. Oberndorfer S. Karzinoide Tumoren des dunndarms. Frankf Z Pathol 1907; 1: 425-32.

5. Overholt SM, Donovan DT, Schwartz MR, Laucirica R, Green LK, Alford BR. Neuroendocrine neoplasms of the larynx. Laryngoscope 1995 Aug; 105 (8 pt1): 789-94.

6. Cuzzort JC, Pezold JC, Dunn CW. Typical carcinoid tumor of the larynx occurring with otalgia: a case report. Ear Nose Throat J 2002 Jan; 81(1): 40 - 3.

7. el-Naggar AK, Batsakis JG. Carcinoid tumor of the larynx. A critical review of the literature. ORL J Otorhinolaryngol Relat Spec. 1991; 53(4): 188-93.

8. Izadi F, Ghanbari H, Nouri HR, Pousti B, Sadeghipour AR. Typical Laryngeal Carcinoid Tumor: A Case report. Iranian Red Crescent Med J 2010; 12(3): 322 - 324

9. Jouhadi H, Mharrech A, Benchakroun N, Tawfiq N, Acharki A, Sahraoui S, Benider A. Typical carcinoid tumor of the larynx. Fr ORL 2006; 91:270 -273.

10. Mani R, Belcadhi M, Chahed H, Ben Abdelkader A, Bouzouita K. Carcinoid tumor of the larynx Ann Otolaryngol Chir Cervicofac. 2009 Apr; 126(2):71-4

11. Bapat U, Mackinnon NA, Spencer MG. Carcinoid tumors of the larynx. Eur Arch Otorhinolaryngol 2005 Mar; 262(3): 194 - 7. 